\title{
Immediate parotid duct reconstruction using an autologous vena comitans of the anterolateral thigh free flap pedicle in ablative head and neck surgery
}

\author{
Jae-Won Kim, Tae-Gon Kim \\ Department of Plastic and Reconstructive Surgery, Yeungnam University Medical Center, Yeungnam University College of Medicine, Daegu, Korea
}

A 44-year-old male patient underwent wide resection due to squamous cell carcinoma of the right cheek and was found to have a defect in the distal parotid duct (Fig. 1A).

Before harvesting the anterolateral thigh (ALT) flap pedicle, we harvested one of the two venae comitantes of sufficient length and anastomosed it to the duct (Fig. 1B, C). The distal end of the reconstructed parotid duct was fixed between the flap and the oral mucosa (Fig. 1D). We inserted a silicone tube to prevent a stricture forming in the suture site of the parotid duct and the neo-duct created using the vena comitans.

When a parotid duct is injured, surgical treatment is recommended to avoid salivary fistulas or sialoceles, and a silicone tube is generally inserted during surgical reconstruction to prevent stricture of the anastomosed duct [1-3]. In previous studies, the mean diameters of the distal portion of the parotid duct, the venae comitantes of ALT flap pedicle were about $1.4 \mathrm{~mm}$ and $2.5 \mathrm{~mm}$, respectively $[4,5]$.

We have reported satisfactory reconstruction outcomes by performing primary parotid duct reconstruction using venae comitantes of the flap pedicle. The study was approved by the Institutional Review Board of Yeungnam University Medical Center (IRB No. YUMC 2018-07-047-001) and performed in accordance with the principles of the Declaration of Helsinki.

Correspondence: Tae-Gon Kim

Department of Plastic and Reconstructive Surgery, Yeungnam University Medical

Center, Yeungnam University College of Medicine, 170 Hyeonchung-ro, Nam-gu,

Daegu 42415, Korea

E-mail: kimtg0919@daum.net

${ }^{\star}$ This work was supported by the 2017 Yeungnam University Research Grant.

Received September 6, 2018 / Revised October 30, 2018 / Accepted November 2, 2018

\section{CONFLICT OF INTEREST}

No potential conflict of interest relevant to this article was reported.

\section{PATIENT CONSENT}

The patient provided written informed consent for the publication and the use of his images.

\section{ORCID}

Jae-Won Kim https://orcid.org/0000-0003-1254-6580

Tae-Gon Kim https://orcid.org/0000-0002-6738-4630

\section{REFERENCES}

1. Steinberg MJ, Herrera AF. Management of parotid duct injuries. Oral Surg Oral Med Oral Pathol Oral Radiol Endod 2005; 99:136-41.

2. Sujeeth S, Dindawar S. Parotid duct repair using an epidural catheter. Int J Oral Maxillofac Surg 2011;40:747-8.

3. Liang CC, Jeng SF, Yeh MC, Liu YT, Kuo YR. Reconstruction of traumatic Stensen duct defect using a vein graft as a conduit: two case reports. Ann Plast Surg 2004;52:102-4.

4. Zenk J, Hosemann WG, Iro H. Diameters of the main excretory ducts of the adult human submandibular and parotid gland: a histologic study. Oral Surg Oral Med Oral Pathol Oral Radiol Endod 1998;85:576-80. 

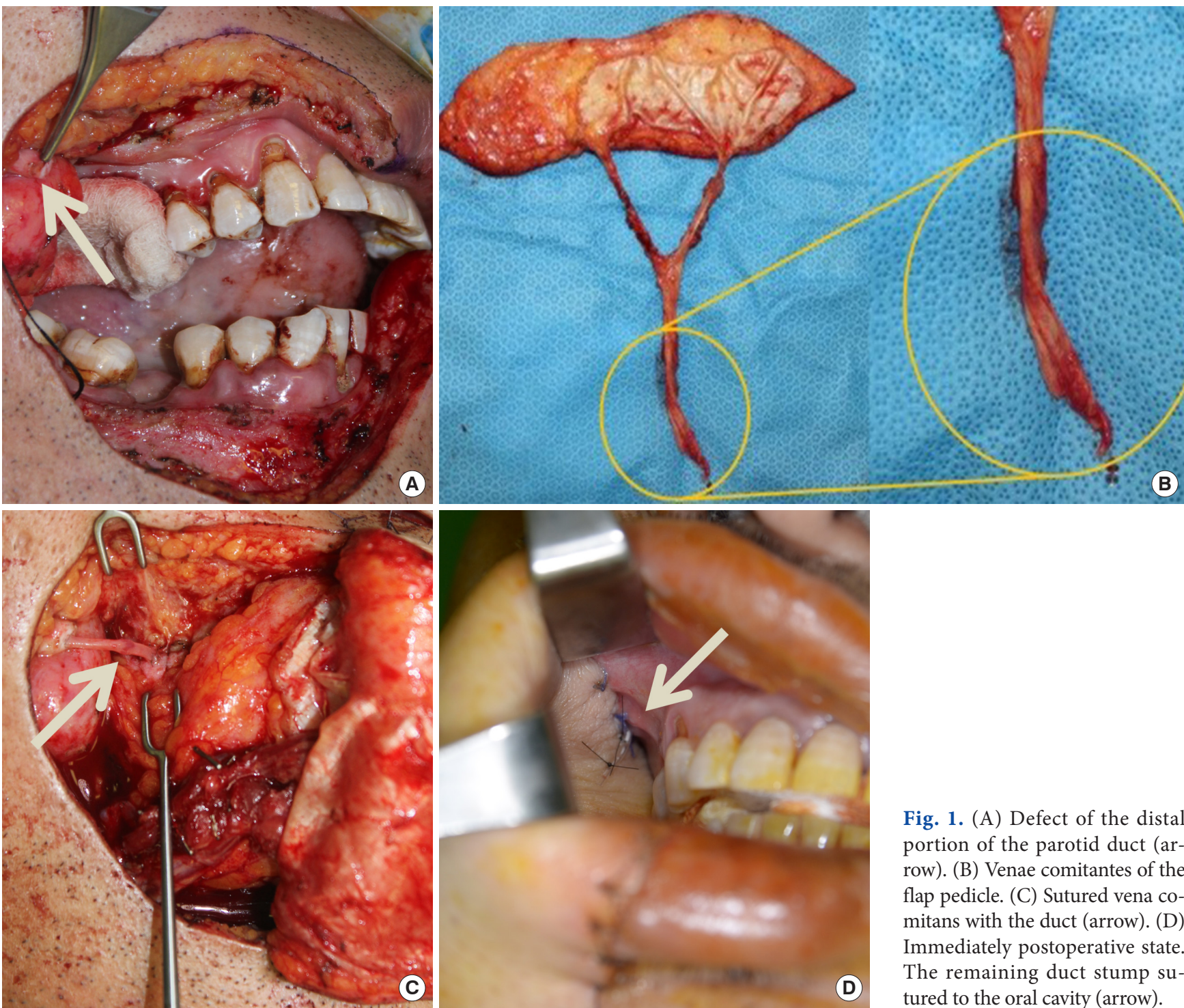

Fig. 1. (A) Defect of the distal portion of the parotid duct (arrow). (B) Venae comitantes of the flap pedicle. (C) Sutured vena comitans with the duct (arrow). (D) Immediately postoperative state. The remaining duct stump sutured to the oral cavity (arrow). 